\title{
ANALYTICAL AND EXPERIMENTAL VIBRATION ANALYSIS OF TELESCOPIC PLATFORMS
}

\author{
Adil Yucel, Alaeddin Arpaci \\ Istanbul Technical University, Department of Mechanical Engineering, Taksin, Istanbul, Turkey \\ e-mail: adil.yucel@itu.edu.tr; arpacial@itu.edu.tr
}

\begin{abstract}
In this study, vibration analysis of a telescopic platform is conducted, and the platform structure is reconstructed to satisfy vibrational standards. The analysis is realised using solid modelling, finite elements and an analytical method. The results are verified using experimental modal techniques. Through the finite element and experimental modal approach free vibration analysis is carried out and natural frequencies are determined. Additionally, vibration accelerations of the structure are obtained by forced vibration analysis of the model. All calculations one performed on the new reconstructed structure, and it is determined whether the reconstructed structure satisfies the vibrational standards.
\end{abstract}

Keywords: telescopic platforms, modal analysis, Finite Element Method, vibration

\section{Introduction}

Platforms are crane-like machines that lift workers and their equipment to desired heights and over various distances. The word 'platform' was only used to describe static structures such as bridges and ladders until the second half of the twentieth century. However, over the past 30 years, various types of platforms have been specified:

- jointed platforms

- trussed platforms

- load platforms

- telescopic platforms

- vertical platforms

In this study, we examine vibrations of telescopic platforms, which are widely used in construction areas, airports and harbours. Telescopic platforms are structures that have at least two long beams, with one sliding within the other, called booms. Usually, the second boom operates through hydraulic cylinders, and the other subsequent booms operate through chains. An example of a telescopic platform with five booms is shown in Fig. 1.

A survey of the literature reveals that many studies have been conducted using the finite element method and three-dimensional modelling. Dayawansa et al. (2004) described cracks that grow in weld joints (called clusters), which protect the booms from catastrophic collapse, and the maintenance and repair techniques used to keep these joints in service. Karahan (2007) designed and analysed a two-level telescopic crane using the finite element method. The parts of the crane were designed in 3D using the Pro ENGINEER software program. The sheet thickness of the main stationary boom carrying the load was determined by performing stress analysis in the ANSYS workbench using the finite element method. Marjamaki and Makinen (2006) extended the idea of modelling a flexible telescopic boom using a non-linear finite element method in 3D. The boom was assembled using Reissner's geometrically exact beam elements. The sliding 


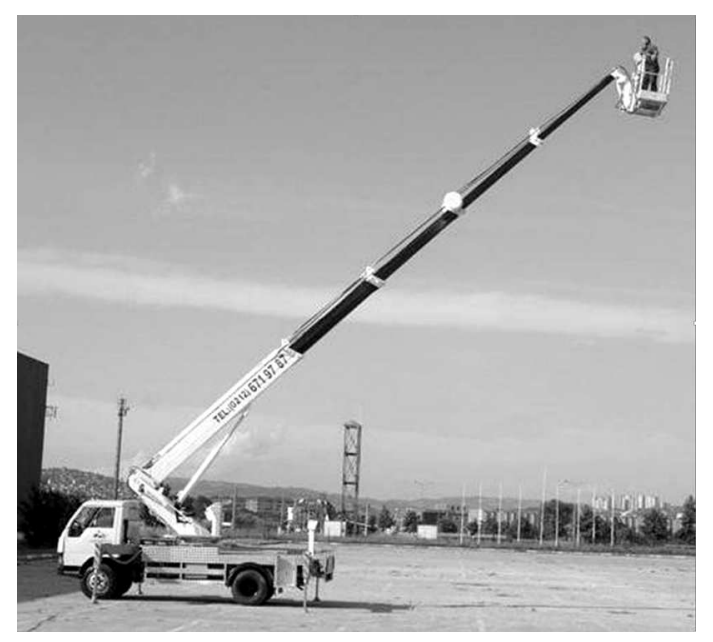

Fig. 1. An example of a five-boom telescopic platform

boom parts were coupled together by the elements where the slide-spring was coupled to the beam with the aid of the master-slave technique. A special element with a revolute joint and an element with an offset were developed. Telescopic movement was achieved by varying the length of the element and the connecting chains. Ozkan (2005) analysed connection points of a frame crane and investigated stress distributions of the connection point components. The commercial finite element package ANSYS was used for finite element analysis. The main objectives of the study conducted by Rusiński et al. (2006) were to discuss design problems associated with machines used in underground mining and to investigate the reasons why these problems arise in the cracked boom of an underground mine machine. Numerical and experimental approaches were pursued. The finite element method was used for numerical simulation. Fractographic and microscopic evaluation, chemical analysis and hardness tests were used to evaluate the materials. The objectives were achieved by numerical simulation of a cracked loader boom, material evaluations of specimens and comparison of the results obtained from both approaches. Numerical simulations were performed based on a discrete model of a jib boom using predefined boundary conditions. The finite element analysis of the jib boom provided information regarding stress distribution under extreme load conditions. The study involved macroscopic and fractographic inspection, microscopic evaluation as well as hardness testing of the materials used for the jib boom. Erdol (2007) performed static finite element analysis and weight optimisation of a box girder, which constitutes approximately $50 \%$ of the total weight of gantry crane structures. Trabka (2014) presented ten variants of a computational model for a telescopic boom crane that differs in the number and selection of flexible components. Modelling and numerical simulations were conducted using the finite element method. In the study, the compatibility of the numerical simulation results and test results of a real structure was qualitatively and quantitatively assessed. Time characteristics and frequency characteristics fter application of the discrete Fourier transformation were also analysed in the study. Posiadała and Cekus (2008) presented one degree of freedom discrete model representing vibration of the telescopic boom of a truck crane in the rotary plane. In the model, the influence of the hydraulic cylinder on the crane radius change was considered. Park and Chang (2004) applied time delay control and commandless input shaping technique, which is a modification-based on the concept of Input Shaping Technique to increase the productivity of the boom of the telescopic handler. Lastly, Sochacki (2007), considered the dynamic stability of a laboratory model of the truck crane. In the study, the results in form of frequency curves for changing the geometry of the system were presented. In this study, vibrational analyses of telescopic platforms are conducted, and these structures are optimised to satisfy vibrational standards. 


\section{Models}

In this study, a telescopic platform with five booms and a maximum operating height of $24 \mathrm{~m}$ has been selected for modelling. The booms are modelled in two different cross-sections: rectangular and annular. The telescopic platform which is was constructed using annular cross sectional booms, is named the 'reconstructed structure' in the study. All of the components of the platform are modelled using the Pro/ENGINEER software. The model consists of the following main parts: foundation, tower, booms, basket joint and basket. The first part that is modelled is the foundation. The foundation is based on a $4920 \times 2100 \mathrm{~mm}$ area, and profiles with cross-sections measuring $80 \times 160 \times 6 \mathrm{~mm}$ are used for modelling where $80 \mathrm{~mm}$ represents height, $160 \mathrm{~mm}$ represents width and $6 \mathrm{~mm}$ represents thickness of the thin-walled rectangular section. The tower is mounted on the foundation using a group of gears located in the reduction gear box. The next part that is modelled is called the tower. The base flange of the tower has thickness of $20 \mathrm{~mm}$. It consists of $16 \times \emptyset 17 \mathrm{~mm}$ holes that are used to mount the gear box. The tower can rotate $360^{\circ}$ around its axis, but its operation angle is limited to $180^{\circ}$. The piston that connects the first boom to the tower is also modelled. The properties of the five booms modelled in this study are presented in Tables 1 and 2 for the rectangular and annular cross-section, respectively. The solid models for the booms with rectangular and annular cross-sections are also presented in Figs. 2 and 3, respectively.

Table 1. Dimensions of the booms with thin-walled rectangular cross-sections

\begin{tabular}{|c|c|c|}
\hline Boom No. & Length $\ell_{i}[\mathrm{~mm}]$ & Cross-section $[\mathrm{mm}]$ \\
\hline \hline 1 & 4580 & $292 \times 510 \times 8$ \\
\hline 2 & 3600 & $250 \times 422 \times 6$ \\
\hline 3 & 3600 & $210 \times 340 \times 5$ \\
\hline 4 & 3600 & $170 \times 260 \times 5$ \\
\hline 5 & 3600 & $132 \times 202 \times 5$ \\
\hline
\end{tabular}

Table 2. Dimensions of the booms with thin-walled annular cross-sections

\begin{tabular}{|c|c|c|}
\hline Boom No. & Length $\ell_{i}[\mathrm{~mm}]$ & Cross-section $[\mathrm{mm}]$ \\
\hline \hline 1 & 4580 & $\emptyset 340 \times 12$ \\
\hline 2 & 3600 & $\emptyset 280 \times 12$ \\
\hline 3 & 3600 & $\emptyset 232 \times 10$ \\
\hline 4 & 3600 & $\emptyset 184 \times 8$ \\
\hline 5 & 3600 & $\emptyset 132 \times 8$ \\
\hline
\end{tabular}

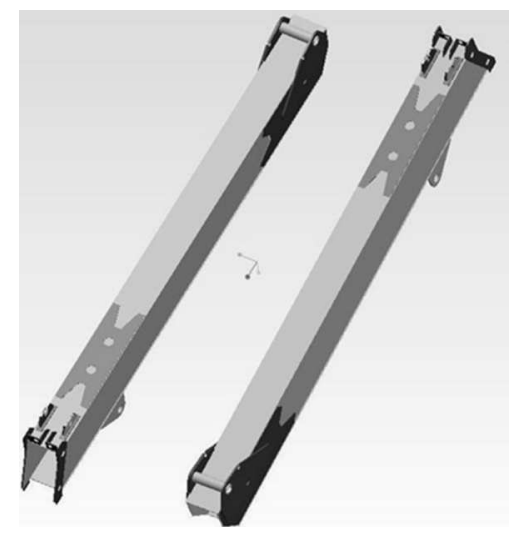

Fig. 2. A boom with a rectangular cross-section 


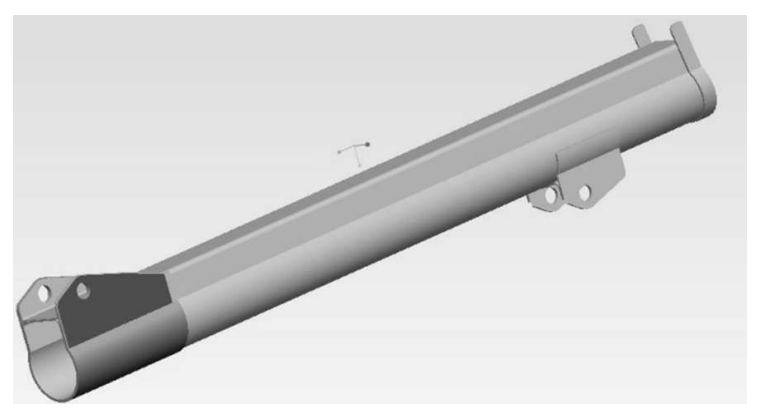

Fig. 3. A boom with an annular cross-section

One of the most important components of the model is the basket joint. The basket joint is the vital part that connects the last boom to the basket in which the worker operates. The last component of the model is the basket in which the work operates. The basket is modelled using $\emptyset 30 \times 2.5 \mathrm{~mm}$ round profiles. It has base area of $900 \times 1500 \mathrm{~mm}$ and height of $1120 \mathrm{~mm}$. The assemblies are constructed both for rectangular and annular section booms.

\section{Finite element analysis for full assemblies}

After the assembled 3D solid model of the telescopic platform is obtained, it is imported into the commercial finite element analysis software program ABAQUS for natural frequency and mode shape analysis. The approximate mesh size of the finite element model is $100 \mathrm{~mm}$. The meshed finite element model is shown in Fig. 4. Linear tetrahedral solid elements are used in the mesh and the material properties are taken as follows:

- density: $7850 \mathrm{~kg} / \mathrm{m}^{3}$

- Poisson's ratio: 0.3

- modulus of elasticity: $210000 \mathrm{MPa}$

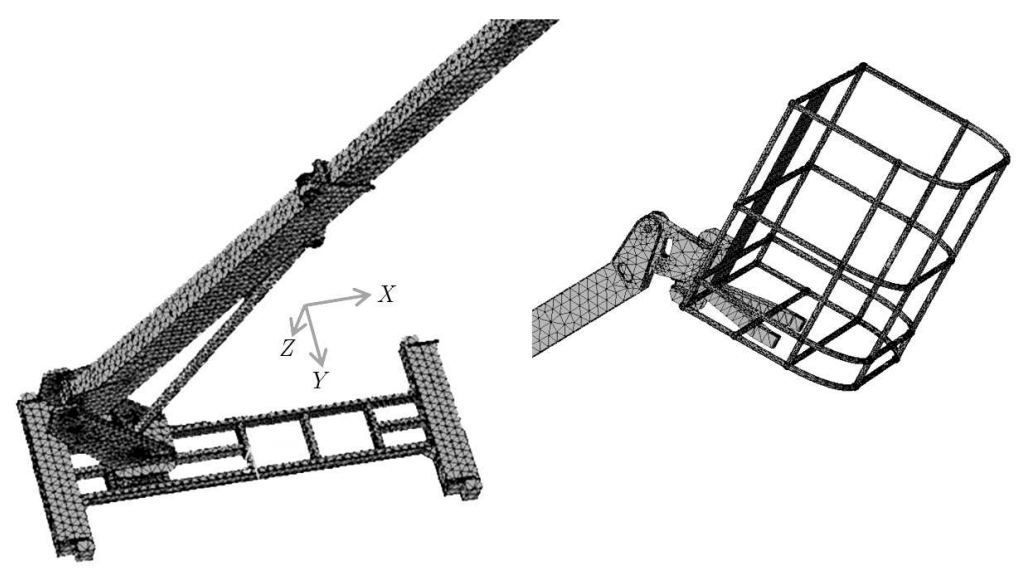

Fig. 4. Finite element model

The first 10 natural frequencies are presented in Table 3. In Table 3, 'ip' and 'op' stand for the in-plane ( $X Z$ plane) and out-of-plane ( $X Y$ plane) mode shapes, respectively.

The source of the excitation is mainly the engine, and the origin of the excitation has been accepted as the foundation; therefore, we conducted the forced vibration finite element analysis by applying the force to the foundation of the platform. The operating (excitation) frequency of the system is $12.875 \mathrm{~Hz}$. This is the frequency of the system when the engine runs idle and the 
Table 3. Natural frequencies

\begin{tabular}{|c|c|c|c|}
\hline $\begin{array}{c}\text { Mode } \\
\text { No. }\end{array}$ & $\begin{array}{c}\text { Natural frequency }[\mathrm{Hz}] \\
\text { (rectangular section) }\end{array}$ & $\begin{array}{c}\text { Natural frequency }[\mathrm{Hz}] \\
\text { (annular section) }\end{array}$ & $\begin{array}{c}\text { Mode } \\
\text { shape }\end{array}$ \\
\hline \hline 1 & 0.2987 & 0.2515 & ip \\
\hline 2 & 0.4196 & 0.2668 & op \\
\hline 3 & 1.1249 & 1.0035 & ip \\
\hline 4 & 1.6382 & 1.0812 & op \\
\hline 5 & 4.9468 & 4.1055 & ip \\
\hline 6 & 7.1794 & 4.4389 & op \\
\hline 7 & 12.125 & 10.105 & ip \\
\hline 8 & 16.929 & 10.988 & op \\
\hline 9 & 21.803 & 18.631 & ip \\
\hline 10 & 31.183 & 19.926 & op \\
\hline
\end{tabular}

workers are working in the basket. As shown in Table 3, the natural frequency is $f=12.125 \mathrm{~Hz}$, which is very close to the operating frequency of the system. This indicates a risk of resonance under operating conditions. Therefore, the model has been reconstructed. After reconstruction (annular boom profile), it has been clearly revealed that there is no natural frequency close to the operating frequency of the system, which validates the reconstruction.

\section{Analytical solution for the five-boom model}

For flexural modes, the boom is modelled as shown in Fig. 5.

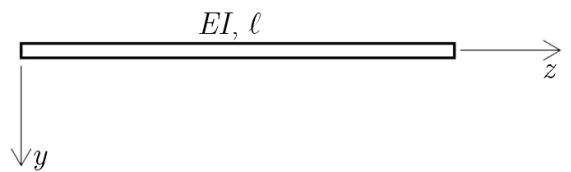

Fig. 5. Analytical model of the boom for flexural modes

Let the deflection in the $y$ direction be $\nu(z, t)$. The equation of vibration for the beam element is given as

$$
E I \frac{\partial^{4} \nu}{\partial z^{4}}+\mu \frac{\partial^{2} \nu}{\partial t^{2}}=0
$$

where $\mu$ is mass per unit length, $\rho$ is mass density, $A$ is cross-sectional area, $t$ is time and EI represents the flexural stiffness. As known

$$
\mu=\rho A
$$

and

$$
\nu(z, t)=\phi(z) \sin (\omega t)
$$

for harmonic motion. Substituting Eq. (4.3) into Eq. (4.1) gives

$$
\frac{\partial^{4} \phi}{\partial z^{4}}-\frac{\mu \omega^{2}}{E I} \phi=0
$$

The solution is

$$
\phi(z)=A \cosh \frac{\lambda z}{\ell}+B \sinh \frac{\lambda z}{\ell}+C \cos \frac{\lambda z}{\ell}+D \sin \frac{\lambda z}{\ell}
$$


where $A, B, C$ and $D$ are the integration constants and

$$
\lambda=\ell \sqrt[4]{\frac{\mu \omega^{2}}{E I}}
$$

For a five-boom structure, the equations are arranged as below. The model of the booms of a telescopic platform with a point mass at the free end is shown in Fig. 6, where $M$ is mass of the point mass, and $J$ is mass moment of inertia of the point mass with respect to the $x$-axis for in-plane and the $y$-axis for out-of-plane analysis

$$
\phi_{i}(z)=A_{i} \cosh \frac{\lambda_{i} z}{\ell_{i}}+B_{i} \sinh \frac{\lambda_{i} z}{\ell_{i}}+C_{i} \cos \frac{\lambda_{i} z}{\ell_{i}}+D_{i} \sin \frac{\lambda_{i} z}{\ell_{i}} \quad i=1,2,3,4,5
$$



Fig. 6. Analytical model of the five-boom structure for flexural modes

Geometric boundary conditions are

$$
\phi_{1}(0)=0 \quad \frac{d \phi_{1}}{d z}(0)=0
$$

Transition boundary conditions are $(i=1,2,3,4)$

$$
\begin{array}{ll}
\phi_{i}\left(\ell_{i}\right)=\phi_{i+1}(0) & \frac{d \phi_{i}}{d z}\left(\ell_{i}\right)=\frac{d \phi_{i+1}}{d z}(0) \\
E I_{i} \frac{d^{2} \phi_{i}}{d z^{2}}\left(\ell_{i}\right)=E I_{i+1} \frac{d^{2} \phi_{i+1}}{d z^{2}}(0) & E I_{i} \frac{d^{3} \phi_{i}}{d z^{3}}\left(\ell_{i}\right)=E I_{i+1} \frac{d^{3} \phi_{i+1}}{d z^{3}}(0)
\end{array}
$$

Natural boundary conditions are

$$
E I_{5} \frac{d^{2} \phi_{5}}{d z^{2}}\left(\ell_{5}\right)-\omega^{2} J \frac{d \phi_{5}}{d z}\left(\ell_{5}\right)=0 \quad E I_{5} \frac{d^{3} \phi_{5}}{d z^{3}}\left(\ell_{5}\right)+\omega^{2} M \phi_{5}\left(\ell_{5}\right)=0
$$

For torsional modes, the boom is modelled as shown in Fig. 7.

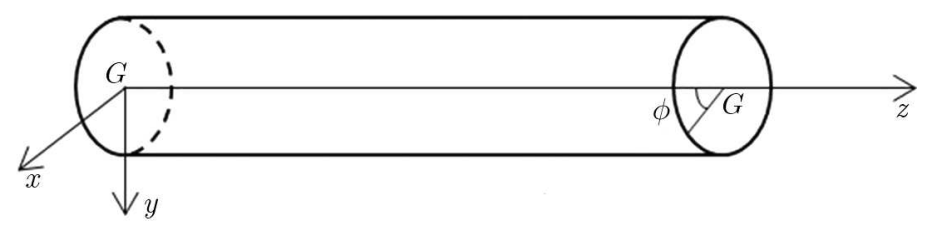

Fig. 7. Analytical model of the boom for torsional modes

Let the twist angle about the $z$-axis be $\varphi(z, t)$. The equation of vibration for the beam element is given as

$$
\varphi=\varphi(z, t) \quad G C \frac{\partial^{2} \varphi}{\partial z^{2}}=\rho I_{p} \frac{\partial^{2} \varphi}{\partial t^{2}}
$$

where $G C$ is the torsional stiffness related to Saint-Venant's principle. For harmonic motion, substituting Eq. (4.12) $)_{1}$ into Eq. (4.11) 2 gives Eq. (4.12) 2

$$
\varphi=\theta(z) \sin (\omega t) \quad c^{2} \frac{\partial^{2} \theta}{\partial z^{2}}+\omega^{2} \theta=0
$$


where

$$
c^{2}=\frac{G C}{I_{p}}
$$

The solution is

$$
\theta(z)=A \sin \frac{\omega z}{c}+B \cos \frac{\omega z}{c}
$$

where $A$ and $B$ are the integration constants. For the booms of the telescopic platform

$$
\theta_{i}\left(z_{i}\right)=A_{i} \sin \frac{\omega z_{i}}{c_{i}}+B_{i} \cos \frac{\omega z_{i}}{c_{i}} \quad c_{i}^{2}=\frac{G C_{i}}{\rho\left(I_{p}\right)_{i}} \quad i=1,2,3,4,5
$$

Geometric boundary conditions are

$$
\theta_{1}(0)=0 \quad \theta_{i}\left(\ell_{i}\right)=\theta_{i+1}(0) \quad i=1,2,3,4
$$

Transition boundary conditions are

$$
G C_{i} \frac{d \theta_{i}}{d z}\left(\ell_{i}\right)=G C_{i+1} \frac{d \theta_{i+1}}{d z}(0) \quad i=1,2,3,4 \quad G C_{5} \frac{d \theta_{5}}{d z}\left(\ell_{5}\right)=0
$$

The results of the finite element analysis and analytical solutions for both rectangular and annular cross-sectional five-boom systems are given in Tables 4-7. In Table 4, 'ip' and 'op' stand for the in-plane and out-of-plane mode shapes, respectively. The value of the point mass is $200 \mathrm{~kg}$, which is the sum of masses of the basket and the worker. The discrepancies in Tables have been calculated according to the formula given below

$$
\text { Dis. }[\%]=\frac{\text { Analytical }- \text { FEA }}{\text { Analytical }} \cdot 100
$$

Table 4. Flexural natural frequencies for rectangular cross-sections

\begin{tabular}{|c|c|c|c|c|c|c|c|}
\hline \multicolumn{2}{|c|}{$\begin{array}{c}\text { Rectangular section } \\
\text { (five-boom without } \\
\text { point mass) }\end{array}$} & \multicolumn{3}{c|}{$\begin{array}{c}\text { Rectangular section } \\
\text { (five-boom with } \\
\text { point mass) }\end{array}$} & $\begin{array}{c}\text { Rectangular } \\
\text { section } \\
\text { (full assembly) }\end{array}$ & $\begin{array}{c}\text { Mode } \\
\text { shape }\end{array}$ \\
\hline FEA & Analytical & Dis. [\%] & FEA & Analytical & Dis. [\%] & FEA & \\
\hline & & & 0.3045 & 0.3134 & 2.84 & 0.2987 & ip \\
\hline & & & 0.4286 & 0.4425 & 3.14 & 0.4196 & op \\
\hline 1.3610 & 1.4180 & 4.02 & 1.1529 & 1.1924 & 3.31 & 1.1249 & op \\
\hline 2.0196 & 2.1049 & 4.05 & 1.6864 & 1.7486 & 3.56 & 1.6382 & op \\
\hline 5.1049 & 5.3411 & 4.42 & 5.1198 & 5.3358 & 4.05 & 4.9468 & op \\
\hline 7.4014 & 7.7389 & 4.36 & 7.4375 & 7.7484 & 4.01 & 7.1794 & op \\
\hline 12.027 & 12.649 & 4.92 & 12.291 & 12.884 & 4.60 & 12.125 & op \\
\hline 17.324 & 18.258 & 5.12 & 17.714 & 18.629 & 4.91 & 16.929 & op \\
\hline 22.285 & 23.643 & 5.74 & 22.862 & 24.182 & 5.46 & 21.803 & op \\
\hline 31.995 & 34.076 & 6.11 & 32.811 & 34.881 & 5.93 & 31.183 & op \\
\hline
\end{tabular}


Table 5. Flexural natural frequencies for annular cross-sections

\begin{tabular}{|c|c|c|c|c|c|c|}
\hline \multicolumn{2}{|c|}{$\begin{array}{c}\text { Annular section } \\
\text { (five-boom without } \\
\text { point mass) }\end{array}$} & \multicolumn{3}{c|}{$\begin{array}{c}\text { Annular cross-section } \\
\text { (five-boom with } \\
\text { point mass) }\end{array}$} & $\begin{array}{c}\text { Annular } \\
\text { cross-section } \\
\text { (full assembly) }\end{array}$ \\
\hline FEA & Analytical & Dis. [\%] & FEA & Analytical & Dis. [\%] & FEA \\
\hline \hline & & & 0.2549 & 0.2691 & 5.28 & 0.2515 \\
\hline 1.2790 & 1.3410 & 4.62 & 1.0224 & 1.0745 & 4.85 & 1.0035 \\
\hline 4.4066 & 4.6309 & 4.84 & 4.2253 & 4.4469 & 4.98 & 4.1055 \\
\hline 10.366 & 11.010 & 5.85 & 10.425 & 11.134 & 6.37 & 10.105 \\
\hline 19.119 & 20.419 & 6.37 & 19.339 & 20.875 & 7.36 & 18.631 \\
\hline 31.444 & 33.434 & 5.95 & 31.584 & 33.926 & 6.90 & 30.105 \\
\hline 48.990 & 52.014 & 5.81 & 48.927 & 52.673 & 7.11 & 46.439 \\
\hline 65.911 & 70.520 & 6.54 & 65.163 & 71.154 & 8.42 & 61.458 \\
\hline
\end{tabular}

Table 6. Torsional natural frequencies for rectangular cross-sections

\begin{tabular}{|c|c|c|c|}
\hline \multicolumn{3}{|c|}{$\begin{array}{c}\text { Rectangular } \\
\text { cross-section } \\
\text { (five-boom model) }\end{array}$} & $\begin{array}{c}\text { Rectangular } \\
\text { cross-section } \\
\text { (full assembly) }\end{array}$ \\
\hline FEA & Analytical & Dis. [\%] & FEA \\
\hline \hline 61.67 & 63.71 & 3.20 & 60.5784 \\
\hline 110.96 & 112.10 & 1.02 & 105.988 \\
\hline 167.98 & 169.81 & 1.08 & 156.036 \\
\hline 214.76 & 230.28 & 6.74 & 190.169 \\
\hline
\end{tabular}

Table 7. Torsional natural frequencies for annular cross-sections

\begin{tabular}{|c|c|c|c|}
\hline \multicolumn{3}{|c|}{$\begin{array}{c}\text { Annular section } \\
\text { (five-boom model) }\end{array}$} & $\begin{array}{c}\text { Annular section } \\
\text { (full assembly) }\end{array}$ \\
\hline FEA & Analytical & Dis. [\%] & FEA \\
\hline \hline 76.44 & 79.47 & 3.81 & 74.7758 \\
\hline 135.92 & 140.40 & 3.19 & 129.100 \\
\hline 204.09 & 210.30 & 2.95 & 186.386 \\
\hline 273.28 & 282.68 & 3.33 & 233.853 \\
\hline
\end{tabular}

\section{Experimental modal analysis}

To conduct forced vibration analysis using the finite element method, we need to determine the excitation force of the system. Due to the restrictions regarding the construction of the telescopic platform, it is impossible to locate a force transducer to measure the excitation force of the system. Instead, we measure the acceleration values of the foundation and basket. Then, we conduct a series of forced vibration analyses using the finite element method to satisfy these acceleration values measured at certain points using sensors on the platform. Thus, we obtain the excitation force value required to further reconstruct the structure. The positions of the sensors on the system are shown in Fig. 8. A B\&K 4524B triaxial CCLD piezoelectric accelerometer with frequency range of $0.25-3000 \mathrm{~Hz}$ and sensitivity of $100 \mathrm{mV} / \mathrm{g}$ has been used in the experiments. FFT analyses are conducted for $0-100 \mathrm{~Hz}$ ( 800 lines $-0.125 \mathrm{~Hz}$ resolution) with sampling rate of $256 \mathrm{~Hz}$ (256 samples per second).

The first triaxial accelerometer is located on the connection part between the foundation and the tower so we obtain the acceleration data for the foundation to create the simulation 

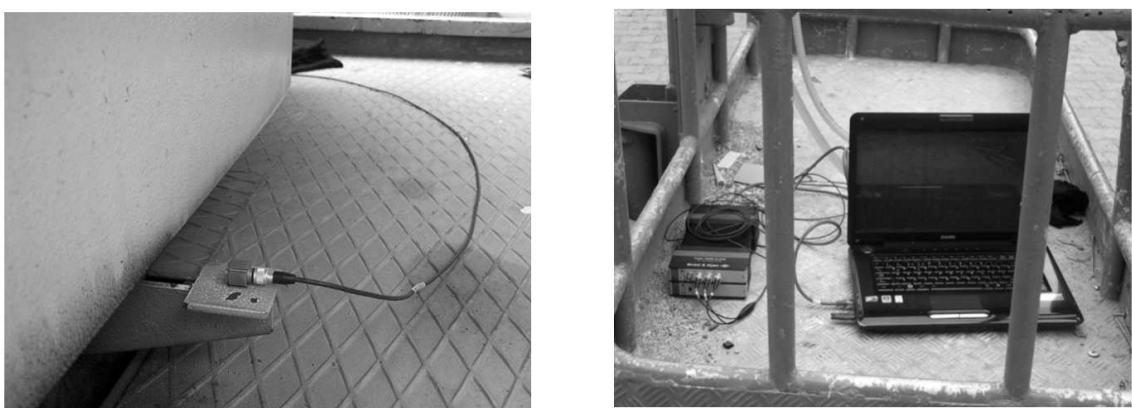

Fig. 8. Locations of the sensors on the foundation and basket

of forced vibration analysis. Secondly, another triaxial accelerometer is located on the floor of the basket to obtain the acceleration data for the basket in order to use in the forced vibration simulation. These data obtained by the measurements on the foundation and basket are then used as reference values in the forced vibration analysis, and a series of forced vibration simulations are carried out to satisfy these reference values. The correct excitation force value is detected when we reach the same values on the foundation and basket as the reference values. This excitation force value which is obtained from forced vibration simulations is then used in the forced vibration simulation of the reconstructed platform model (annular boom profile). Thus, both models have been excited by the same and correct excitation force for the forced vibration simulations.

The results of spectral analyses of the acceleration data obtained by the sensors on the foundation and basket are shown in Figs. 9 and 10.

(a)

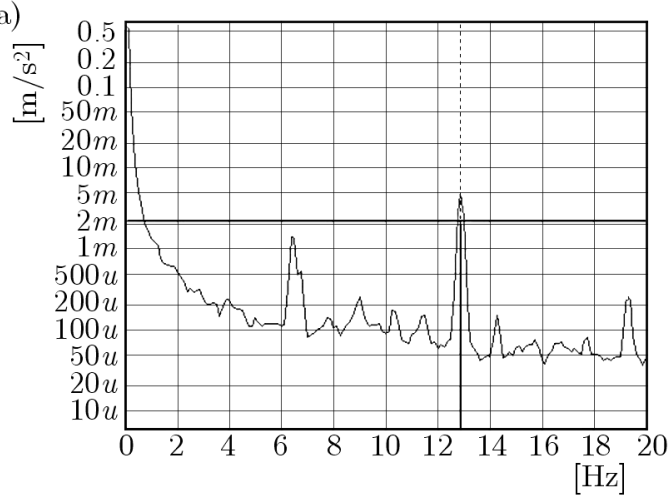

(b)

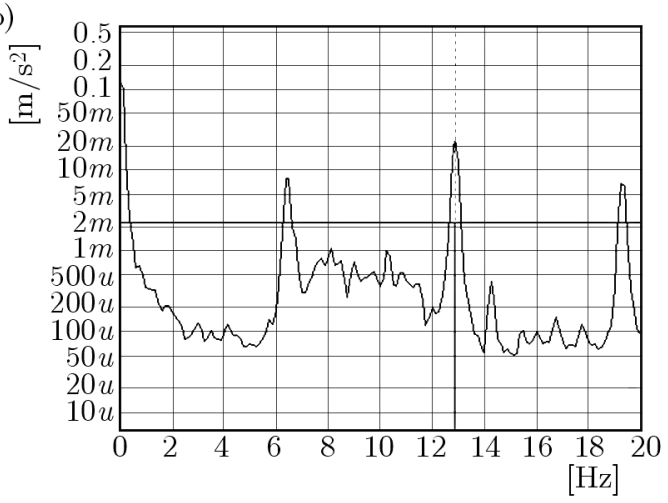

(c)

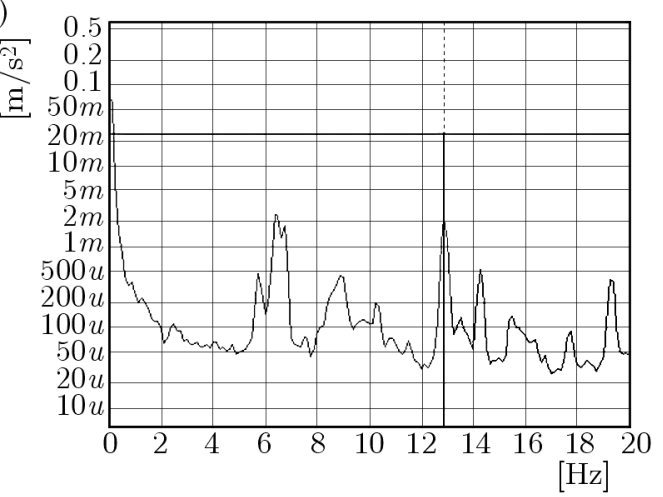

Fig. 9. Spectral analysis of foundation vibration of the telescopic platform: (a) $X$ direction,

(b) $Y$ direction, (c) $Z$ direction 


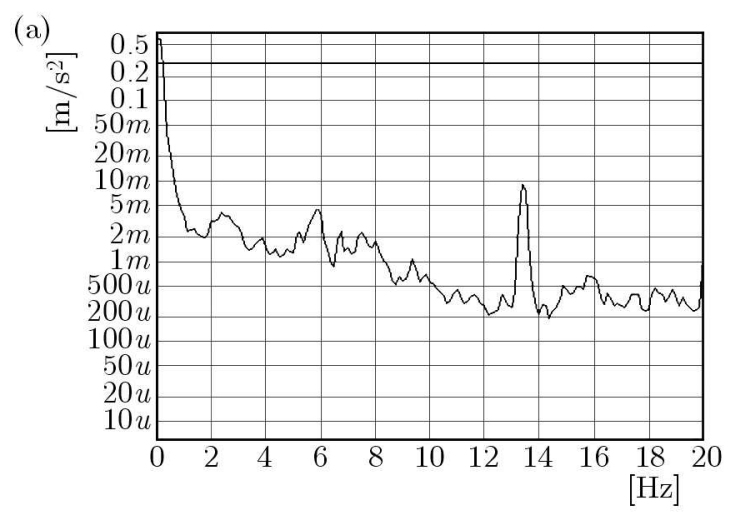

(b)

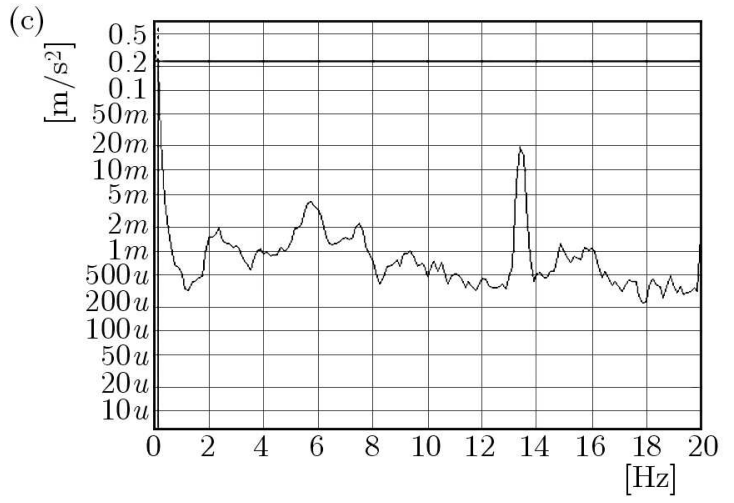

Fig. 10. Spectral analysis of basket vibration of the telescopic platform: (a) $X$ direction,

(b) $Y$ direction, (c) $Z$ direction

The main units written at the top of the axes in Fig. 9 and Fig. 10 are m/s $\mathrm{s}^{2} \cdot 2 m$ means $2 \mathrm{~mm} / \mathrm{s}^{2}$ where $m$ stands for $\mathrm{mm} .500 u$ means $500 \mu \mathrm{m} / \mathrm{s}^{2}$ where $u$ stands for $\mu \mathrm{m}$.

Using the results of spectral analysis, the acceleration values at the operating frequency have been determined. They are presented in Table 8 .

Table 8. Experimentally obtained acceleration values at the operating frequency

\begin{tabular}{|c|c|c|}
\hline Direction & $\begin{array}{c}\text { Foundation } \\
{\left[\mathrm{mm} / \mathrm{s}^{2}\right]}\end{array}$ & $\begin{array}{c}\text { Basket } \\
{\left[\mathrm{mm} / \mathrm{s}^{2}\right]}\end{array}$ \\
\hline \hline$X$ & 5.004 & 9.173 \\
\hline$Y$ & 24.455 & 5.494 \\
\hline$Z$ & 2.203 & 19.532 \\
\hline
\end{tabular}

Having realised the forced vibration analysis using the finite element method to satisfy the acceleration values, the distributed excitation force is determined to be $8.52 \cdot 10^{-6} \mathrm{ton} / \mathrm{mm}^{2}$ $(0.0836 \mathrm{MPa})$. This force has been used to analyse both assembly models (with rectangular and annular boom profiles).

\section{Conclusions}

In this study, vibrational analysis of a telescopic platform has been conducted. This structure has been reconstructed to satisfy vibrational standards (applying to the industrial safety regulations) and shift resonance frequencies. The vibrational analyses are conducted using solid modelling, finite elements and an analytical method. The results of the analysis are also verified using the experimental modal technique. 
The operating (excitation) frequency of the system is $12.875 \mathrm{~Hz}$. The table of natural frequencies of the original model indicates that there is a natural frequency value of $12.125 \mathrm{~Hz}$ that is very close to the operating frequency of the system. This reveals a risk of resonance under operating conditions. After reconstruction, it has been clearly revealed that there is no natural frequency close to the operating frequency of the system, which validates the reconstruction.

Although it is impossible to locate a force transducer on the system and to measure the acting force, the distributed force has been determined to be $8.52 \cdot 10^{-6}$ ton $/ \mathrm{mm}^{2}(0.0836 \mathrm{MPa})$ using experimental modal analysis by taking the acceleration values obtained experimentally into account. We measured the accelerations in different points of the system and then conducted a series of forced vibration finite element analyses with different force values until we achieved the acceleration values obtained by the experiments. This force value can be used in any modal analysis of this model.

By examining the related standard, it has been observed that the acceleration values on the basket are very high for workers. After the reconstruction, we observed a significant reduction in the acceleration values. The acceleration values on the basket before and after reconstruction are presented in Table 9. According to the related standard (ISO 2631), which defines the maximum allowed acceleration values for a worker, the acceleration values on the basket after reconstruction stay considerably under the limits for the operating frequency.

Table 9. Comparison of acceleration values on the basket

\begin{tabular}{|c|c|c|}
\hline Direction & $\begin{array}{c}\text { Rectangular cross-cection } \\
\text { (original) }\left[\mathrm{mm} / \mathrm{s}^{2}\right]\end{array}$ & $\begin{array}{c}\text { Annular cross-section } \\
\text { (reconstructed) }\left[\mathrm{mm} / \mathrm{s}^{2}\right]\end{array}$ \\
\hline \hline$X$ & 9.597 & 1.358 \\
\hline$Y$ & 5.709 & 1.267 \\
\hline$Z$ & 20.636 & 3.528 \\
\hline
\end{tabular}

Tables 4-7 indicate that five-boom analytical models can be accepted instead of full assemblies because parts other than the booms have little effect on the frequencies. Therefore, we can agree that the telescopic platform can be taken as a connection of beams with varying cross-sections for frequency calculations. The results also show that the point mass, which replaces the masses of the basket and workers in the analytical model, causes very little difference on natural frequencies but only changes the mode shapes. The point mass has no effect on torsional modes.

\section{Acknowledgments}

We want to thank Ms. Elif Naz Aladag and Mr. Mehmet Ozaltinoglu for their supports in the preparation of solid models and analyses files.

\section{References}

1. Dayawansa P., Chitty G., Kerezsi B., Bartosiewicz H., Price J.W.H., 2004, Fracture mechanics of mining dragline booms, Structural Integrity and Fracture: Proceedings of the International Conference, SIF2004, Brisbane, Australia

2. Erdol T., 2007, Design, analysis of the gantry crane with finite element method and box girder optimization, Master's Thesis, Gebze Institute of Technology, Gebze, Turkey

3. Karahan M., 2007, Design and finite element analysis of two levels telescopic crane, Master's Thesis, Ataturk University, Erzurum, Turkey

4. Marjamaki H., Makinen J., 2006, Modelling a telescopic boom - the 3D case: Part II, Computers \& Structures, 84, 29, 2001-2015 
5. Ozkan I., 2005, Computer aided design and analysis of frame crane, Master's Thesis, Dokuz Eylul University, Izmir, Turkey

6. Rusiński E., Czmochowski J. Moczko, P., 2006, Numerical and experimental analysis of a mine's loader boom crack, Journal of Achievements in Materials and Manufacturing Engineering, 17, 1/2, 273-276

7. Sochacki W., 2007, The dynamic stability of a laboratory model of a truck crane, Thin-Walled Structures, 45, 927-930

8. PosiadaŁa B., Cekus D., 2008, Discrete model of vibration of truck crane telescopic boom with consideration of the hydraulic cylinder of crane radius change in the rotary plane, Automation in Construction, 17, 245-250

9. PARK J.Y., Chang P.H., 2004, Vibration control of a telescopic handler using time delay control and commandless input shaping technique, Control Engineering Practice, 12, 769-780

10. Trabka A., 2014, Dynamics of telescopic cranes with flexible structural components, International Journal of Mechanical Sciences, 88, 162-174

Manuscript received July 16, 2014; accepted for print June 20, 2015 